Original Research Paper

\title{
$\beta$-Naphthalene Incorporated Thiazole-5- Carboxamides/Thiazole -5- Ketones: Design, Synthesis and Anticonvulsant Screening against Two Seizure Models
}

\author{
${ }^{1}$ Mohammed Faiz Arshad, ${ }^{2}$ Faisal Al-Otaibi, ${ }^{1}$ Gulam Mustafa, \\ ${ }^{3}$ Saad Shousha and ${ }^{4}$ Abdulrahman Alshahrani \\ ${ }^{1}$ Department of Pharmaceutical Sciences, College of Pharmacy, Shaqra University, Dawadmi, Kingdom of Saudi Arabia \\ ${ }^{2}$ Department of Clinical Pharmacy, College of Pharmacy, Shaqra University, Dawadmi, Kingdom of Saudi Arabia \\ ${ }^{3}$ Department of Physiology, Faculty of Veterinary Medicine, Benha University, 13736 Moshtohor, Egypt \\ ${ }^{4}$ College of Medicine, Shaqra, Shaqra University, Kingdom of Saudi Arabia
}

Article history

Received: 26-01-2019

Revised: 29-04-2019

Accepted: 28-08-2019

Corresponding Author:

Mohammed Faiz Arshad

Department of Pharmaceutical

Sciences, College of Pharmacy,

Shaqra University, Dawadmi,

Kingdom of Saudi Arabia

Tel: 00966594082153

Email: drfaizarshad@gmail.com

\begin{abstract}
A bunch of $\beta$-naphthalene incorporated thiazole-5carboxamides/thiazole -5- ketones (7a-7o\& 8a-8e) were prepared by reacting 4-methyl-2-(naphthalen-2-yl)thiazole-5-carbonyl chloride with appropriate amines. Structures of all the compounds were explained by elemental analysis, FT-IR, 1H NMR and mass spectral data. The compounds were evaluated for their anticonvulsant activity employing MES and chemoshock ( $s c$ PTZ) seizure tests. Neurotoxicity was also assessed. Majority of these compounds exhibited significant activity against both animal models; however, compounds $\mathbf{7 e}, \mathbf{7 j}, \mathbf{7 n}$ and $8 \mathbf{c}$ displayed promising activity and could be considered as leads for further investigations.
\end{abstract}

Keywords: Thiazole, MES, scPTZ, Anticonvulsant Activity

\section{Introduction}

Epilepsy is a group of neurological conditions which has characteristics of epileptic seizures (Chang and Lowenstein, 2003; Robert et al., 2014). Epileptic seizures are episodes that can differ from brief and nearly unnoticeable to long periods of forceful shaking. In the brain, epilepsy causes unusual release of neurotransmitters due to which the electrical working of brain gets disturbed prompting muscle spasm, nausea, convulsions and loss of consciousness (Al-Otaibi, 2019). It can be triggered by brain injuries, tumours, high fevers or strokes. In a substantial number of epilepsies, hereditary factor also plays an important role in the development of seizures.

Approximately 65 million people in the world are impacted by various types of epilepsy (Thurman et al., 2011). The occurrence of epilepsy and other seizure related disorders in Saudi population was assessed approximately $0.65 \%$ (Al-Rajeh et al., 2001). The lacks of single fundamental mechanism in case of epilepsy and, the multifactorial origin of the disease create much more difficulty in developing new antiepileptic drugs. Furthermore, treatment of various epilepsies and particularly the partial one, which is the most common type, present a continuous headache to the drug developers. The typical antiepileptic drugs comprise phenobarbital, phenytoin, carbamazepine and valproic acid have been existing in several European countries since 1960s (Hess, 1985). All these currently accessible antiepileptic drugs have neurological toxicity and idiosyncratic side effects (Brodie, 1990). The search for new antiepileptic compounds with more selectivity and lower toxicity is uninterruptedly an area of investigation for medicinal chemists. The important and highly effective approach to treat epilepsy is the identification of new targets through better understanding of molecular mechanisms of epilepsy.

In the last two decades, several new naphthalene analogues were synthesized for antiepileptic screening. The first naphthalene derivative developed as an antiepileptic agent was nafimidone. Nafimidone, a derivative of imidazole was discovered in early eighties, having structurally different class with exclusive properties. Till now, studies have revealed that nafimidone is a potent anticonvulsant than phenytoin. But the problems with the drug are huge in terms of its toxicity and low potency. The drug inhibits carbamazepine and phenytoin metabolism which in turn, leads to severe toxicity. Considering nafimidone as lead, various analogues of nafimidone or similar compounds were synthesized in recent years (Fig. 1; I, II, III and IV) and promising anticonvulsant results were observed with less toxicity (Karakurt et al., 2001; 2006; 2010; 2012; Ozdemir et al., 2014). The optimization of nafimidone is continued in the hope that the potent and less toxic nafimidone derivative will usher a new era of antiepileptic drug development. 
<smiles>O=C(Cn1ccnc1)c1ccc2ccccc2c1</smiles>

Nafimidone<smiles>[R]O/N=C(/Cn1ccnc1)c1ccc2ccccc2c1</smiles>

I<smiles>[R]O/N=C(\Cn1ncnc1[R])c1ccc2ccccc2c1</smiles>

II<smiles>[R]C(=O)OC(Cn1ccnc1)c1ccc2cccc([R])c2c1</smiles>

III<smiles>[R]C(=O)O/N=C(/Cn1ccnc1)c1ccc2ccccc2c1</smiles>

Fig. 1: Recently synthesized promizing antiepileptic agents

In our study, $\beta$-naphthalene incorporated thiazole-5carboxamide derivatives were aimed on the basis of structural similarities with nafimidone. Furthermore, the imidazole moiety of nafimidone was replaced with thiazole ring with the expectation to improve the bioactivity since thiazole possessed neuroprotective as well as antiseizure activity (Koufaki et al., 2007; Amin et al., 2008). The presence of sulfur moiety in the thiazole ring may facilitate the drugs to cross the Blood Brain Barrier (BBB) due to lipophilic nature and exhibit more anticonvulsant activity.

To understand the possible mode of action of substituted napthalenyl-thiazole derivatives at the molecular level, we carried out molecular docking simulations studies of synthesized molecules (7a-7o\&8a$8 \mathrm{e})$ at the GABA aminotransferase catalytic ligand binding site. For the validation of docking parameters, the rosmarinic acid, a well-known gamma amino butyric acid (GABA) transaminase inhibitor was docked at the catalytic site of protein and the root-mean-square deviation (RMSD) between co-crystal and docked pose was found to be $0.255 \AA$ (less than $2 \AA$ ).

\section{Experimental}

\section{Chemical Synthesis}

The melting points were determined in open capillary tubes in a Hicon melting point device and are not changed. Elemental analysis was performed on a Vario-EL III CHNOS- Elemental analyzer and the results were within $\pm 0.4 \%$ of the theoretical values of elements. The Fourier Transform Infrared (FTIR) spectra were documented in $\mathrm{KBr}$ pellets on a Jasco FT/IR 410 spectrometer and the values were attributed in inverse centimeter $\left(v_{\max }-\mathrm{cm}^{-1}\right)$. The ${ }^{1} \mathrm{H}$ NMR spectra were taken on a Bruker model dpx 300 (300 $\mathrm{MHz}$ ) NMR spectrometer and chemical shifts $(\delta)$ are presented in part per million (ppm) from the peak of Tetramethylsilane (TMS) which is used as reference standard. Mass spectra were taken on a Bruker Ion trap (Esquire 3000) mass spectrophotometer. The consistency of the compounds was checked by Thin Layer Chromatography (TLC) on silica gel G (Merck) coated plates by using toluene: Ethyl acetate: Formic acid $(5: 4: 1)$ as solvent system. The TLC spots were visualized by using iodine chamber and UV lamp. Lipophilicity $(\log P)$ was measured using ACD lab software version 12.0. The docking simulations study of synthesized compounds was performed using Maestro, version 9.4 implemented from Schrodinger software suite. The protein structure for docking study was obtained from protein data bank (PDB ID: 1OHW) and prepared by eliminating solvent, adding hydrogen and further energy minimization was achieved in the presence of bound ligand using protein preparation software. The ligands were sketched in 3D format using build panel and 
were prepared for docking, making use of Ligprep application. Docking of title compounds were performed using Glide extra-precision (XP) mode, with up to three poses saved per molecule.

\section{Synthesis of Naphthalene-2-Carbonitrile (2)}

To a mixture of hydroxylamine hydrochloride $(0.515 \mathrm{~mol})$ and sodium formate $(0.687 \mathrm{~mol})$ in formic acid (anhydrous, $300 \mathrm{~mL}$ ), 2-naphthaldehyde $(0.343$ mol) was mixed and the reaction blend was heated to $100^{\circ} \mathrm{C}$ for almost eight hours. After completion of reaction, the reaction mixture was cooled down to about $40^{\circ} \mathrm{C}$ and water was mixed. The reaction blend was cooled to about $25^{\circ} \mathrm{C}$ and agitated for about $1 \mathrm{~h}$. The solid precipitated was strained, washed with water and dehydrated. The solid was then dissolved in acetone at about $50^{\circ} \mathrm{C}$ and water was mixed slowly over a time of about $30 \mathrm{~min}$. The mixture was cooled to about $25^{\circ} \mathrm{C}$ and again agitated for about $1 \mathrm{~h}$. The solid thus collected was strained, washed with acetone and water (1:1) mixture and dehydrated to obtain the title product.

\section{Synthesis of Naphthalene-2-Carbothioamide (3)}

To a suspension of sodium hydrosulfide $(\mathrm{NaSH})$ (hydrate, $70 \%$ w/w $)(11.98 \mathrm{~g}, 0.150 \mathrm{~mol})$ and $\mathrm{MgCl} 2.6 \mathrm{H} 2 \mathrm{O}$ (15.20 g, $0.075 \mathrm{~mol})$ in DMF (100 $\mathrm{mL}), 2$-nitrile naphthalene $(0.075 \mathrm{~mol})$ was added. The reaction blend was agitated at $20^{\circ} \mathrm{C}$ for $18 \mathrm{~h}$ and progress of reaction was checked on TLC. On finishing point of the reaction, the mixture was added in water $(200 \mathrm{~mL})$. The precipitated solid was washed with water and then agitated in $\mathrm{IN} \mathrm{HCl}(200 \mathrm{~mL})$ for 20 min. After filtration and washing with water, the product was crystallized from toluene and hexane, obtaining the title compound, as a yellow solid. Yield: $79 \%$, mp: $144^{\circ} \mathrm{C}$.

\section{Synthesis of Ethyl 4-Methyl-2-(Naphthalen-2-yl) Thiazole-5-Carboxylate (4)}

Naphthalene-2-carbothioamide $(0.069 \mathrm{~mol})$ was dissolved in EtOH $(130 \mathrm{~mL})$ and to this, ethyl-2choroacetoacetate $(9.5 \mathrm{~mL}, 11.30 \mathrm{~g}, 0.069 \mathrm{~mol})$ was added. The reaction blend was refluxed for 16 hours. When the starting compound was completely finished, the reaction blend was cooled to room temperature and the product was strained. Crystal formation of intermediate was done from ethanol, obtaining a white solid at the bottom of the container. Yield: $71 \%$; m.p.: $185^{\circ} \mathrm{C},{ }^{1} \mathrm{H}-\mathrm{NMR}\left(300 \mathrm{MHz}, \mathrm{DMSO}-\mathrm{d}_{6}\right): \delta 2.66(\mathrm{~s}, 3 \mathrm{H}$, $\left.\mathrm{CH}_{3}\right), 1.34\left(\mathrm{t}, 3 \mathrm{H}, \mathrm{CH}_{2} \mathrm{CH}_{3}\right), 4.32\left(\mathrm{q}, 2 \mathrm{H}, \mathrm{CH}_{2} \mathrm{CH}_{3}\right)$, 7.62-7.65 (m, 2H, Ar-H), 7.89-7.93 (m, 2H, Ar-H), 8.048.07 (m, 2H, Ar-H), 8.32 (s, 1H, Ar-H); ESI-MS m/z $297.08\left(\mathrm{M}^{+}\right), 253.98,226.17$
4-Methyl-2-(Naphthalen-2-yl)

Thiazole-5-

\section{Carboxylic Acid (5)}

To a mixture of ethanol $(25 \mathrm{~m})$ and THF $(05 \mathrm{ml})$ containing ethyl 4-methyl-2-(naphthalen-2-yl) thiazole-5-carboxylate (compound 4, $0.01 \mathrm{~mol}$ ), $2 \mathrm{ml}$ of $1 \mathrm{~N} \mathrm{NaOH}$ was mixed and content was refluxed for $8 \mathrm{hr}$. After the reaction is complete the mixture was checked by TLC, the solvent was removed under evaporation and the residue was neutralized by $1 \mathrm{~N}$ $\mathrm{HCl}$ to $\mathrm{pH} 2-3$. The precipitated solid was strained, washed with water and crystal formation was done from aqueous ethanol. Yield: $68 \%$; m.p.: $154^{\circ} \mathrm{C} ;{ }^{1} \mathrm{H}-\mathrm{NMR}(300$ MHz, DMSO- $\left.d_{6}\right): \delta 2.65\left(\mathrm{~s}, 3 \mathrm{H}, \mathrm{CH}_{3}\right), 7.65-7.68(\mathrm{~m}, 2 \mathrm{H}$, Ar-H), 7.86-7.90 (m, 2H, Ar-H), 8.05-8.08 (m, 2H, Ar-H), 8.35 (s, 1H, Ar-H), 10.56 (s, 1H, COOH); ESI-MS m/z $269.05\left(\mathrm{M}^{+}\right), 253.92,226.26$.

\section{Synthesis of 4-Methyl-2-(Naphthalen-2-yl) Thiazole-5-Carbonyl Chloride (6)}

To a mixture of 4-methyl-2-(naphthalen-2-yl) thiazole-5-carboxylic acid (compound 5) (0.02 mol) in dry toluene in $50 \mathrm{ml} \mathrm{RBF}$, thionyl chloride $(0.06 \mathrm{~mol})$ was added. The resulting blend was refluxed for about 4 hour. The status of the reaction was checked by TLC using TEF as solvent system. At the end of the reaction the extra thionyl chloride was eliminated by distillation under low pressure. The crude acyl chloride was obtained and crystal formation was done from ethanol. Yield: $72 \%$; m.p.: $174{ }^{\circ} \mathrm{C},{ }^{1} \mathrm{H}-\mathrm{NMR}$ (300 MHz, DMSO$\left.\mathrm{d}_{6}\right): \delta 2.64\left(\mathrm{~s}, 3 \mathrm{H}, \mathrm{CH}_{3}\right), 7.69-7.72(\mathrm{~m}, 2 \mathrm{H}, \mathrm{Ar}-\mathrm{H}), 7.87-$ $7.91(\mathrm{~m}, 2 \mathrm{H}, \mathrm{Ar}-\mathrm{H}), 8.02-8.06(\mathrm{~m}, 2 \mathrm{H}, \mathrm{Ar}-\mathrm{H}), 8.30(\mathrm{~s}$, 1H, Ar-H); ESI-MS m/z $289.01(\mathrm{M}+2), 287.02\left(\mathrm{M}^{+}\right)$, 254.15, 226.12.

\section{General Method for Synthesis of Compounds (7a- $7 o ; 8 a-8 e)$}

To a solution of appropriate amine $(52.0 \mathrm{mmol})$ in dry pyridine $(50 \mathrm{ml})$ at room temperature, a solution of 4-methyl-2-(naphthalen-2-yl)thiazole-5-carbonyl

chloride (compound 6) $(50.0 \mathrm{mmol})$ in dehydrated acetone $(50 \mathrm{~mL})$ was mixed. After the addition, the reaction blend was constantly agitated for 4-6 h. The status of the reaction was checked by TLC using TEF $(5: 4: 1)$ as solvent system. At the end of the reaction, crude mixture was added into ice water $(100 \mathrm{~mL})$. The precipitate collected was agitated, washed with cold water and dehydrated to obtain desired compound. The crystal formation of the compound was done from methanol or ethanol. Figure 2 describes the synthetic scheme of the title compounds 7a-7o and 8a-8e. 


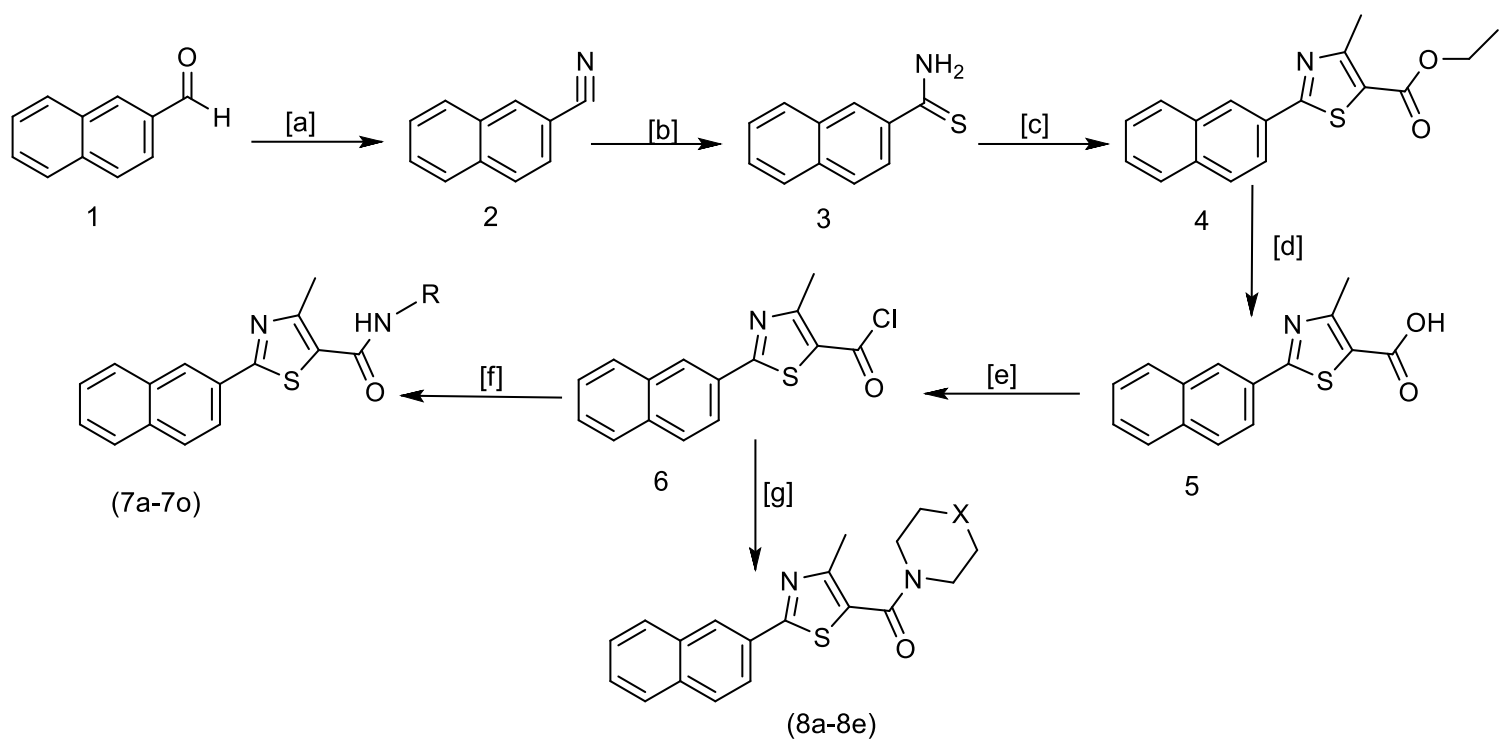

Fig. 2: Synthesis of the title compounds (7a-o \& 8a-e); Reagents and conditions: [a] $\mathrm{NH}_{2} \mathrm{OH}, \mathrm{HCl}, \mathrm{HCOONa} / \mathrm{HCOOH}$, [b] NaSH, $\mathrm{MgCl}_{2}$, [c] $\mathrm{CH}_{3} \mathrm{COCHClCOOC}_{2} \mathrm{H}_{5} /$ ethanol [d] THF/C2 $\mathrm{H}_{5} \mathrm{OH}, \mathrm{NaOH} / \mathrm{HCl}$, [e] SOCl2, [f] ArNH2/Pyridine [g] HNC4H8X 7a: $\mathrm{R}=$ $\mathrm{C}_{6} \mathrm{H}_{5}, 7 \mathbf{b}: \mathrm{R}=4 \mathrm{CH}_{3}-\mathrm{C}_{6} \mathrm{H}_{4-}, 7 \mathbf{c}: \mathrm{R}=4 \mathrm{Cl}-\mathrm{C}_{6} \mathrm{H}_{4-}, 7 \mathbf{7}: \mathrm{R}=4 \mathrm{~F}-\mathrm{C}_{6} \mathrm{H}_{4^{-}}, 7 \mathrm{e}: \mathrm{R}=4 \mathrm{Br}_{-} \mathrm{C}_{6} \mathrm{H}_{4-}, 7 \mathbf{f}: \mathrm{R}=4 \mathrm{NO}_{3}-\mathrm{C}_{6} \mathrm{H}_{4-}, 7 \mathbf{g}: \mathrm{R}=4 \mathrm{OCH}_{3-}$ $\mathrm{C}_{6} \mathrm{H}_{4-}, 7 \mathbf{h}: \mathrm{R}=4 \mathrm{OH}-\mathrm{C}_{6} \mathrm{H}_{4-}, 7 \mathbf{i}: \mathrm{R}=3 \mathrm{Cl}, 4 \mathrm{~F}-\mathrm{C}_{6} \mathrm{H}_{3-}, 7 \mathbf{j}: \mathrm{R}=3,4-\mathrm{diCl}_{-} \mathrm{C}_{6} \mathrm{H}_{3^{-}}, 7 \mathbf{k}: \mathrm{R}=2 \mathrm{OH}-\mathrm{C}_{6} \mathrm{H}_{4^{-}}, 7 \mathbf{7 l}: \mathrm{R}=2 \mathrm{~F}-\mathrm{C}_{6} \mathrm{H}_{4^{-}}, 7 \mathbf{m}: \mathrm{R}^{2}=2 \mathrm{CH}_{3^{-}}$ $\mathrm{C}_{6} \mathrm{H}_{4},-7 \mathbf{n}: \mathrm{R}=4 \mathrm{NH}_{2} \mathrm{SO}_{2}-\mathrm{C}_{6} \mathrm{H}_{4-}, 7 \mathbf{z}: \mathrm{R}=$ Cyclohexyl-, 8a: $\mathrm{X}=\mathrm{CH}_{2}, \mathbf{8 b}: \mathrm{X}=\mathrm{O}, \mathbf{8 c}: \mathrm{X}=\mathrm{S}, \mathbf{8 d}: \mathrm{X}=\mathrm{NCH}_{3}, \mathbf{8 e}: \mathrm{X}=\mathrm{NCH}_{2} \mathrm{Cl}$

\section{4-Methyl-2-(Naphthalen-2-yl)-N-Phenylthiazole-5- Carboxamide (7a)}

Yield: $65 \%$; mp: $157^{\circ} \mathrm{C}, \operatorname{LogP}: 5.33$, FT-IR $v_{\max }$ ( $\mathrm{cm}^{-1}, \mathrm{KBr}$ pellets): $3378(\mathrm{NH}), 1687(\mathrm{C}=\mathrm{O}), 1623(\mathrm{C}$ $=\mathrm{C}), 1590(\mathrm{C}=\mathrm{N}) .{ }^{1} \mathrm{H}-\mathrm{NMR}$ (300 MHz, DMSO- $\left.d_{6}\right): \delta$ $2.64\left(\mathrm{~s}, 3 \mathrm{H}, \mathrm{CH}_{3}\right), 7.08-7.11(\mathrm{~m}, 1 \mathrm{H}, \mathrm{Ar}-\mathrm{H}), 7.51(\mathrm{~d}, 2 \mathrm{H}$, Ar-H, J = Hz), 7.58-7.62 (m, 4H, Ar-H), 7.87-7.91 (m, 2H, Ar-H), 8.05-8.08 (m, 2H, Ar-H), 8.34 (s, 1H, Ar-H), 12.67 (s, 1H, CONH); ESI-MS $\mathrm{m} / z$ 344.10, 253.95, 226.19. Anal. Calcd for $\mathrm{C}_{21} \mathrm{H}_{16} \mathrm{~N}_{2} \mathrm{OS}$ : C, 73.23; H, 4.68; N, 8.13. Found: C, 73.44, H, 4.69; N, 8.17.

\section{4-Methyl-2-(Naphthalen-2-yl)-N-p-Tolylthiazole-5- Carboxamide ( $7 \boldsymbol{b})$}

Yield: 59\%; mp: $174^{\circ} \mathrm{C}, \log \mathrm{P}: 5.79$, FT-IR $v_{\max }$ $\left(\mathrm{cm}^{-1}, \mathrm{KBr}\right.$ pellets): $3367(\mathrm{NH}), 1680(\mathrm{C}=\mathrm{O}), 1626(\mathrm{C}$ $=\mathrm{C}), 1593(\mathrm{C}=\mathrm{N}) .{ }^{1} \mathrm{H}-\mathrm{NMR}\left(300 \mathrm{MHz}, \mathrm{DMSO}-d_{6}\right): \delta$ $2.25\left(\mathrm{~s}, 3 \mathrm{H}, \mathrm{CH}_{3}\right), 2.66$ (s, 3H, $\left.\mathrm{CH}_{3}\right), 7.25$ (d, $2 \mathrm{H}, \mathrm{Ar}-\mathrm{H}$, $\mathrm{J}=\mathrm{Hz})$, 7.54-7.59 (m, 4H, Ar-H), 7.89-7.92 (m, 2H, Ar$\mathrm{H}), 8.09-8.11(\mathrm{~m}, 2 \mathrm{H}, \mathrm{Ar}-\mathrm{H}), 8.30(\mathrm{~s}, 1 \mathrm{H}, \mathrm{Ar}-\mathrm{H}), 12.44$ (s, 1H, CONH); ESI-MS m/z 358.11, 253.91, Anal. Calcd for $\mathrm{C}_{22} \mathrm{H}_{18} \mathrm{~N}_{2} \mathrm{OS}$ : C, 73.71; H, 5.06; N, 7.82. Found: C, 73.50; H, 5.08; N, 7.87.

$\mathrm{N}$-(4-Chlorophenyl)-4-Methyl-2-(Naphthalen-2-yl) Thiazole-5-Carboxamide (7c)

Yield: $68 \%$; mp: $168^{\circ} \mathrm{C}, \log P: 6.12$, FT-IR $v_{\max }\left(\mathrm{cm}^{-1}\right.$, $\mathrm{KBr}$ pellets): $3363(\mathrm{NH}), 1688(\mathrm{C}=\mathrm{O}), 1623(\mathrm{C}=\mathrm{C})$, $1589(\mathrm{C}=\mathrm{N}) .{ }^{1} \mathrm{H}-\mathrm{NMR}\left(300 \mathrm{MHz}, \mathrm{DMSO}-\mathrm{d}_{6}\right): \delta 2.66$ $\left(\mathrm{s}, 3 \mathrm{H}, \mathrm{CH}_{3}\right), 7.42(\mathrm{~d}, 2 \mathrm{H}, \mathrm{Ar}-\mathrm{H}, \mathrm{J}=\mathrm{Hz}), 7.57-7.60(\mathrm{~m}, 2 \mathrm{H}$, $\mathrm{Ar}-\mathrm{H})$, 7.74-7.73 (m, 2H, Ar-H, J = Hz), 7.85-7.90 (m, $2 \mathrm{H}, \mathrm{Ar}-\mathrm{H}), 8.10-8.13$ (m, 2H, Ar-H), 8.36 (s, 1H, Ar-H), 12.57(s, 1H, CONH); ESI-MS m/z 380.09 (M+2), 378.06 $\left(\mathrm{M}^{+}\right)$, 254.09, 226.69. Anal. Calcd for $\mathrm{C}_{21} \mathrm{H}_{15} \mathrm{ClN}_{2} \mathrm{OS}$ : C, 66.57; H, 3.99; N, 7.39. Found: C, 67.73; H, 7.97; N, 7.43.

N-(4-Fluorophenyl)-4-Methyl-2-(Naphthalen-2-yl) Thiazole-5-Carboxamide (7d)

Yield: $72 \%$; mp: $140^{\circ} \mathrm{C}, \operatorname{LogP}: 5.78$, FT-IR $v_{\max }$ $\left(\mathrm{cm}^{-1}, \mathrm{KBr}\right.$ pellets): $3370(\mathrm{NH}), 1690(\mathrm{C}=\mathrm{O}), 1628(\mathrm{C}$ $=\mathrm{C}), 1596(\mathrm{C}=\mathrm{N}) \cdot{ }^{1} \mathrm{H}-\mathrm{NMR}\left(300 \mathrm{MHz}, \mathrm{DMSO}-\mathrm{d}_{6}\right): \delta$ $2.65\left(\mathrm{~s}, 3 \mathrm{H}, \mathrm{CH}_{3}\right), 7.26(\mathrm{~d}, 2 \mathrm{H}, \mathrm{Ar}-\mathrm{H}, \mathrm{J}=\mathrm{Hz}), 7.57-7.64$ (m, 4H, Ar-H), 7.87-7.92 (m, 2H, Ar-H), 8.06-8.10 (m, $2 \mathrm{H}, \mathrm{Ar}-\mathrm{H}), 8.33$ (s, 1H, Ar-H), 12.51 (s, 1H, CONH); ESI-MS m/z 362.09, 254.15, 226.30 Anal. Calcd for $\mathrm{C}_{21} \mathrm{H}_{15} \mathrm{FN}_{2} \mathrm{OS}$ : C, 69.59; H, 4.17; N, 7.73. Found: C, 69.33; H, 4.19; N, 7.77.

N-(4-Bromophenyl)-4-Methyl-2-(Naphthalen-2-yl) Thiazole-5-Carboxamide (7e)

Yield: $66 \%$; mp: $159^{\circ} \mathrm{C}, \log \mathrm{P}: 6.50, \mathrm{FT}-\mathrm{IR} \quad v_{\max }$ $\left(\mathrm{cm}^{-1}, \mathrm{KBr}\right.$ pellets): $3368(\mathrm{NH}), 1683(\mathrm{C}=\mathrm{O}), 1620(\mathrm{C}$ $=\mathrm{C}), 1592(\mathrm{C}=\mathrm{N}) \cdot{ }^{1} \mathrm{H}-\mathrm{NMR}\left(300 \mathrm{MHz}, \mathrm{DMSO}-\mathrm{d}_{6}\right): \delta$ $2.66\left(\mathrm{~s}, 3 \mathrm{H}, \mathrm{CH}_{3}\right), 7.32$ (d, $\left.2 \mathrm{H}, \mathrm{Ar}-\mathrm{H}, \mathrm{J}=\mathrm{Hz}\right), 7.62-7.67$ $(\mathrm{m}, 4 \mathrm{H}, \mathrm{Ar}-\mathrm{H}), 7.88-7.91(\mathrm{~m}, 2 \mathrm{H}, \mathrm{Ar}-\mathrm{H}), 8.06-8.10(\mathrm{~m}$, $2 \mathrm{H}, \mathrm{Ar}-\mathrm{H}), 8.36(\mathrm{~s}, 1 \mathrm{H}, \mathrm{Ar}-\mathrm{H}), 12.62(\mathrm{~s}, 1 \mathrm{H}, \mathrm{CONH})$; ESI-MS m/z $424.04(\mathrm{M}+2), 422.01\left(\mathrm{M}^{+}\right), 253.86$, 226.08. Anal. Calcd for $\mathrm{C}_{21} \mathrm{H}_{15} \mathrm{BrN}_{2} \mathrm{OS}$ : $\mathrm{C}, 59.58 ; \mathrm{H}$, 3.57; N, 6.62. Found: C, 59.76; H, 3.59; N, 6.60. 
4-Methyl-2-(Naphthalene-2-yl)-N-(4-Nitrophenyl) Thiazole-5-Carboxamide (7f)

Yield: $70 \%$; mp: $175^{\circ} \mathrm{C}, \operatorname{LogP}: 5.42$, FT-IR $v_{\max }$ $\left(\mathrm{cm}^{-1}, \mathrm{KBr}\right.$ pellets): $3370(\mathrm{NH}), 1679(\mathrm{C}=\mathrm{O}), 1618(\mathrm{C}$ $=\mathrm{C}), 1596(\mathrm{C}=\mathrm{N}) .{ }^{1} \mathrm{H}-\mathrm{NMR}\left(300 \mathrm{MHz}, \mathrm{DMSO}-\mathrm{d}_{6}\right): \delta$ 2.67 (s, 3H, $\left.\mathrm{CH}_{3}\right), 7.62-7.68(\mathrm{~m}, 4 \mathrm{H}, \mathrm{Ar}-\mathrm{H}), 7.86-7.93$ $(\mathrm{m}, 2 \mathrm{H}, \mathrm{Ar}-\mathrm{H}), 8.05-8.12(\mathrm{~m}, 4 \mathrm{H}, \mathrm{Ar}-\mathrm{H}), 8.34(\mathrm{~s}, 1 \mathrm{H}$, Ar-H), 12.60 (s, 1H, CONH); ESI-MS m/z 389.08, 254.20, 226.22. Anal. Calcd for $\mathrm{C}_{21} \mathrm{H}_{15} \mathrm{~N}_{3} \mathrm{O}_{3} \mathrm{~S}$ : C, 64.77; H, 3.88; N, 10.79. Found: C, 64.48; H, 3.89; N, 10.85 .

N-(4-Methoxyphenyl)-4-Methyl-2-(Naphthalen-2yl) Thiazole-5-Carboxamide (7g)

Yield: 59\%; mp: $180^{\circ} \mathrm{C}, \operatorname{LogP}: 5.28$,FT-IR $v_{\max }$ ( $\mathrm{cm}^{-1}, \mathrm{KBr}$ pellets): $3362(\mathrm{NH}), 1683(\mathrm{C}=\mathrm{O}), 1622(\mathrm{C}$ $=\mathrm{C}), 1591(\mathrm{C}=\mathrm{N}) \cdot{ }^{1} \mathrm{H}-\mathrm{NMR}\left(300 \mathrm{MHz}, \mathrm{DMSO}-\mathrm{d}_{6}\right): \delta$ $2.65\left(\mathrm{~s}, 3 \mathrm{H}, \mathrm{CH}_{3}\right), 3.89\left(\mathrm{~s}, 3 \mathrm{H}, \mathrm{CH}_{3}\right), 7.05-7.08(\mathrm{~d}, 2 \mathrm{H}$, $\mathrm{Ar}-\mathrm{H}, \mathrm{J}=\mathrm{Hz}), 7.67-7.72(\mathrm{~m}, 4 \mathrm{H}, \mathrm{Ar}-\mathrm{H}), 7.83-7.86(\mathrm{~m}$, $2 \mathrm{H}, \mathrm{Ar}-\mathrm{H}), 8.09-8.12(\mathrm{~m}, 2 \mathrm{H}, \mathrm{Ar}-\mathrm{H}), 8.36(\mathrm{~s}, 1 \mathrm{H}, \mathrm{Ar}-\mathrm{H})$, 12.63 (s, 1H, CONH); ESI-MS m/z 374.11, 226.30. Anal. Calcd for $\mathrm{C}_{22} \mathrm{H}_{18} \mathrm{~N}_{2} \mathrm{O}_{2} \mathrm{~S}$ : C, 70.57; H, 4.85; N, 7.48. Found: C, 70.72; H, 4.86; N, 7.53.

$\mathrm{N}$-(4-Hydroxyphenyl)-4-Methyl-2-(Naphthalen-2yl) Thiazole-5-Carboxamide (7h)

Yield: $62 \%$; mp: $149^{\circ} \mathrm{C}, \log \mathrm{P}: 4.59, \mathrm{FT}-\mathrm{IR} \quad v_{\max }$ ( $\mathrm{cm}^{-1}, \mathrm{KBr}$ pellets): $3366(\mathrm{NH}), 1689(\mathrm{C}=\mathrm{O}), 1620(\mathrm{C}$ $=\mathrm{C}), 1597(\mathrm{C}=\mathrm{N}) .{ }^{1} \mathrm{H}-\mathrm{NMR}\left(300 \mathrm{MHz}, \mathrm{DMSO}-\mathrm{d}_{6}\right): \delta$ $2.64\left(\mathrm{~s}, 3 \mathrm{H}, \mathrm{CH}_{3}\right), 7.00-7.03(\mathrm{~d}, 2 \mathrm{H}, \mathrm{Ar}-\mathrm{H}, \mathrm{J}=\mathrm{Hz}), 7.64-$ 7.70 (m, 3H, Ar-H), 7.88-7.91 (m, 2H, Ar-H), 8.03-8.06 (m, $2 \mathrm{H}, \operatorname{Ar}-\mathrm{H}), 8.32(\mathrm{~s}, 1 \mathrm{H}, \operatorname{Ar}-\mathrm{H}), 9.30(\mathrm{~s}, 1 \mathrm{H}, \mathrm{OH})$, 12.69 (s, $1 \mathrm{H}, \mathrm{CONH}$ ); ESI-MS m/z 360.09, 254.12, 226.34 Anal. Calcd for $\mathrm{C}_{21} \mathrm{H}_{16} \mathrm{~N}_{2} \mathrm{O}_{2} \mathrm{~S}$ : C, 69.98; H, 4.47; N, 7.77. Found: C, 69.70; H, 4.45; N, 7.81.

$\mathrm{N}$-(3-Chloro-4-Fluorophenyl)-4-Methyl-2-

(Naphthalen-2-yl) Thiazole-5-Carboxamide (7i)

Yield: $75 \%$; mp: $188^{\circ} \mathrm{C}, \log \mathrm{P}: 7.02$, FT-IR $v_{\max }$ $\left(\mathrm{cm}^{-1}, \mathrm{KBr}\right.$ pellets): $3373(\mathrm{NH}), 1684(\mathrm{C}=\mathrm{O}), 1619(\mathrm{C}$ $=\mathrm{C}), 1594(\mathrm{C}=\mathrm{N}) .{ }^{1} \mathrm{H}-\mathrm{NMR}\left(300 \mathrm{MHz}, \mathrm{DMSO}^{-} \mathrm{d}_{6}\right): \delta$ $2.65\left(\mathrm{~s}, 3 \mathrm{H}, \mathrm{CH}_{3}\right), 7.44-7.49(\mathrm{~m}, 2 \mathrm{H}, \mathrm{Ar}-\mathrm{H}), 7.63-7.66$ (m, 2H, Ar-H), 7.85-7.90 (m, 3H, Ar-H), 8.06-8.09 (m, $2 \mathrm{H}, \mathrm{Ar}-\mathrm{H}), 8.37$ (s, 1H, Ar-H), $12.58(\mathrm{~s}, 1 \mathrm{H}, \mathrm{CONH})$; ESI-MS m/z $398.02(\mathrm{M}+2), 396.05\left(\mathrm{M}^{+}\right), 254.04$, 226.15. Anal. Calcd for $\mathrm{C}_{21} \mathrm{H}_{14} \mathrm{ClFN}_{2} \mathrm{OS}$ : C, 63.55; $\mathrm{H}$, 3.56; N, 7.06. Found: C, 63.74; H, 3.58; N, 7.13.

$\mathrm{N}-(3, \quad 4-D i c h l o r o p h e n y l)-4-M e t h y l-2-(N a p h t h a l e n-$ 2-yl) Thiazole-5-Carboxamide (7j)

Yield: $73 \%$; mp: $195^{\circ} \mathrm{C}, \operatorname{LogP}: 7.13$, FT-IR $v_{\max }$ $\left(\mathrm{cm}^{-1}, \mathrm{KBr}\right.$ pellets): $3370(\mathrm{NH}), 1681(\mathrm{C}=\mathrm{O}), 1622$ $(\mathrm{C}=\mathrm{C}), 1592(\mathrm{C}=\mathrm{N}) .{ }^{1} \mathrm{H}-\mathrm{NMR}\left(300 \mathrm{MHz}, \mathrm{DMSO}-\mathrm{d}_{6}\right): \delta$ $2.67\left(\mathrm{~s}, 3 \mathrm{H}, \mathrm{CH}_{3}\right), 7.59-7.67(\mathrm{~m}, 4 \mathrm{H}, \mathrm{Ar}-\mathrm{H}), 7.83-7.87$ (m, 2H, Ar-H), 8.00-8.06 (m, 3H, Ar-H), $8.34(\mathrm{~s}, 1 \mathrm{H}$, Ar-H), 12.60 (s, 1H, CONH); ESI-MS m/z 416.05 (M+4), 414.07 (M+2) 412.02 (M+), 253.90, 226.25 Anal. Calcd for $\mathrm{C}_{21} \mathrm{H}_{14} \mathrm{Cl}_{2} \mathrm{~N}_{2} \mathrm{OS}$ : C, 61.02; H, 3.41; N, 6.78. Found: C, $61.25 \mathrm{H}, 3.42 ; \mathrm{N}, 6.83$.

\section{N-(2-Hydroxyphenyl)-4-Methyl-2-(Naphthalen-2- yl) Thiazole-5-Carboxamide (7k)}

Yield: $61 \%$; mp: $163^{\circ} \mathrm{C}, \operatorname{LogP}: 5.34$, FT-IR $v_{\max }$ ( $\mathrm{cm}^{-1}, \mathrm{KBr}$ pellets): $3368(\mathrm{NH}), 1687(\mathrm{C}=\mathrm{O}), 1623(\mathrm{C}$ = C), $1597(\mathrm{C}=\mathrm{N}) .{ }^{1} \mathrm{H}-\mathrm{NMR}(300 \mathrm{MHz}, \mathrm{DMSO}-\mathrm{d} 6): \delta$ 2.64 (s, 3H, $\left.\mathrm{CH}_{3}\right), 7.09-7.15$ (m, 3H, Ar-H), 7.64-7.73 (m, 4H, Ar-H), 7.86-7.90 (m, 2H, Ar-H), 8.03-8.07 (m, 2H, Ar-H), $8.36(\mathrm{~s}, 1 \mathrm{H}, \mathrm{Ar}-\mathrm{H}), 12.64(\mathrm{~s}, 1 \mathrm{H}, \mathrm{CONH})$; ESI-MS m/z 360.07, 254.31, 226.10. Anal. Calcd for $\mathrm{C}_{21} \mathrm{H}_{16} \mathrm{~N}_{2} \mathrm{O}_{2} \mathrm{~S}$ : C, 69.98; H, 4.47; N, 7.77. Found: C, 69.76; H, 4.49; N, 7.72.

\section{$N$-(2-Fluorophenyl)-4-Methyl-2-(Naphthalen-2-yl) Thiazole-5-Carboxamide (7l)}

Yield: 69\%; mp: $145^{\circ} \mathrm{C}, \operatorname{LogP}: 5.30$, FT-IR $v_{\max }$ $\left(\mathrm{cm}^{-1}, \mathrm{KBr}\right.$ pellets): $3373(\mathrm{NH}), 1689(\mathrm{C}=\mathrm{O}), 1629(\mathrm{C}$ $=\mathrm{C}), 1607(\mathrm{C}=\mathrm{N}) .{ }^{1} \mathrm{H}-\mathrm{NMR}\left(300 \mathrm{MHz}, \mathrm{DMSO}-\mathrm{d}_{6}\right): \delta$ $2.67\left(\mathrm{~s}, 3 \mathrm{H}, \mathrm{CH}_{3}\right), 7.12-7.19(\mathrm{~m}, 3 \mathrm{H}, \mathrm{Ar}-\mathrm{H}), 7.67-7.70$ (m, 2H, Ar-H), 7.86-7.92 (m, 3H, Ar-H), 8.09-8.12 (m, $2 \mathrm{H}, \mathrm{Ar}-\mathrm{H}), 8.35(\mathrm{~s}, 1 \mathrm{H}, \mathrm{Ar}-\mathrm{H}), 12.60(\mathrm{~s}, 1 \mathrm{H}, \mathrm{CONH})$; ESI-MS m/z 362.09, 253.99, 226.14. Anal. Calcd for $\mathrm{C}_{21} \mathrm{H}_{15} \mathrm{FN}_{2} \mathrm{OS}$ : C, 69.59; H, 4.17; N, 7.73. Found: $\mathrm{C}$, 69.74; H, 4.18; N, 7.78.

\section{4-Methyl-2-(Naphthalen-2-yl)-N-o-Tolylthiazole-5- Carboxamide (7m)}

Yield: $64 \%$; mp: $139^{\circ} \mathrm{C}, \operatorname{LogP}: 5.79$, FT-IR $v_{\max }$ $\left(\mathrm{cm}^{-1}, \mathrm{KBr}\right.$ pellets): $3361(\mathrm{NH}), 1684(\mathrm{C}=\mathrm{O}), 1620(\mathrm{C}=$ C), $1595(\mathrm{C}=\mathrm{N}) .{ }^{1} \mathrm{H}-\mathrm{NMR}\left(300 \mathrm{MHz}, \mathrm{DMSO}-\mathrm{d}_{6}\right): \delta 2.24$ (s, 3H, $\left.\mathrm{CH}_{3}\right), 2.64$ (s, 3H, $\left.\mathrm{CH}_{3}\right), 7.08-7.10(\mathrm{~m}, 1 \mathrm{H}, \mathrm{Ar}-\mathrm{H})$, 7.35-7.41 (m, 3H, Ar-H), 7.64-7.68 (m, 2H, Ar-H), 7.847.87 (m, 2H, Ar-H), 8.05-8.09 (m, 2H, Ar-H), 8.37 (s, 1H, $\mathrm{Ar}-\mathrm{H}), 12.68(\mathrm{~s}, 1 \mathrm{H}, \mathrm{CONH}) ; \mathrm{ESI}-\mathrm{MS} \mathrm{m} / \mathrm{z}$ 358.11, 253.68, 226.47. Anal. Calcd for $\mathrm{C}_{22} \mathrm{H}_{18} \mathrm{~N}_{2} \mathrm{OS}$ : C, 73.71; H, 5.06; N, 7.82. Found: C, 73.85; H, 5.04; N, 7.88.

\section{4-Methyl-2-(Naphthalen-2-yl)-N-(4-Sulfamoyl- Phenyl) Thiazole-5-Carboxamide (7n)}

Yield: 76\%; mp: $201^{\circ} \mathrm{C}, \operatorname{LogP}: 4.14$, FT-IR $v_{\max }$ $\left(\mathrm{cm}^{-1}, \mathrm{KBr}\right.$ pellets):3373 $(\mathrm{NH}), 1692(\mathrm{C}=\mathrm{O}), 1625(\mathrm{C}$ = C), $1570(\mathrm{C}=\mathrm{N}) .{ }^{1} \mathrm{H}-\mathrm{NMR}(300 \mathrm{MHz}$, DMSO-d6): $\delta 2.02\left(\mathrm{~s}, 2 \mathrm{H}, \mathrm{NH}_{2}\right), 2.48\left(\mathrm{~s}, 3 \mathrm{H}, \mathrm{CH}_{3}\right), 7.37-7.39(\mathrm{~d}$, $2 \mathrm{H}, \operatorname{Ar}-\mathrm{H}, \mathrm{J}=\mathrm{Hz}), 7.62-7.64(\mathrm{~d}, 2 \mathrm{H}, \mathrm{Ar}-\mathrm{H}, \mathrm{J}=\mathrm{Hz})$, 7.80-7.93 (m, 4H, Ar-H), 7.98-8.0 (d, 2H, Ar-H, J = $\mathrm{Hz}), 8.27$ (s, 1H, Ar-H), 9.30 (s, 1H, CONH); ESI-MS $\mathrm{m} / \mathrm{z}$ 423.50, 254.28, 226.33. Anal. Calcd for $\mathrm{C}_{21} \mathrm{H}_{17} \mathrm{~N}_{3} \mathrm{O}_{3} \mathrm{~S}_{2}$ : C, 59.56; H, 4.05; N, 9.92. Found: $\mathrm{C}$, $59.43 ; \mathrm{H}, 4.03 ; \mathrm{N}, 9.96$. 


\section{N-(Cyclohexyl)-4-Methyl-2-(Naphthalene-2-yl)}

Thiazole-5-Carboxamide (7o)

Yield: $67 \%$; mp: $178^{\circ} \mathrm{C}, \operatorname{LogP}: 5.63$, FT-IR $v_{\max }$ $\left(\mathrm{cm}^{-1}, \mathrm{KBr}\right.$ pellets $): 3365(\mathrm{NH}), 1680(\mathrm{C}=\mathrm{O}), 1623(\mathrm{C}$ = C), $1598(\mathrm{C}=\mathrm{N}) .{ }^{1} \mathrm{H}-\mathrm{NMR}\left(300 \mathrm{MHz}, \mathrm{DMSO}-\mathrm{d}_{6}\right): \delta$ 1.39-1.45 (m, 6H, 2xCH 2$), 1.81-1.89\left(\mathrm{~m}, 4 \mathrm{H}, 2 \mathrm{xCH}_{2}\right)$, $2.66\left(\mathrm{~s}, 3 \mathrm{H}, \mathrm{CH}_{3}\right), 7.66-7.69(\mathrm{~m}, 2 \mathrm{H}, \mathrm{Ar}-\mathrm{H}), 7.82-7.89$ $(\mathrm{m}, 4 \mathrm{H}, \mathrm{Ar}-\mathrm{H}), 8.04-8.07(\mathrm{~m}, 2 \mathrm{H}, \mathrm{Ar}-\mathrm{H}), 8.36(\mathrm{~s}, 1 \mathrm{H}$, Ar-H), 12.61 (s, 1H, CONH); ESI-MS m/z 350.15, 253.89, 226.40. Anal. Calcd for $\mathrm{C}_{20} \mathrm{H}_{20} \mathrm{~N}_{2} \mathrm{OS}$ : C, 71.97; H, 6.33; N, 7.99. Found: C, 71.76; H, 6.35; N, 8.04.

\section{4-Methyl-2-(Naphthalene-2-yl) Thiazol-5-yl) (Piperidin-1-yl) Methanone (8a)}

Yield: $80 \%$; mp: $170^{\circ} \mathrm{C}, \operatorname{LogP}: 4.15$, FT-IR $v_{\max }\left(\mathrm{cm}^{-1}\right.$, $\mathrm{KBr}$ pellets): $1677(\mathrm{C}=\mathrm{O}), 1624(\mathrm{C}=\mathrm{C}), 1589(\mathrm{C}=\mathrm{N})$. ${ }^{1} \mathrm{H}-\mathrm{NMR}\left(300 \mathrm{MHz}, \mathrm{DMSO}-\mathrm{d}_{6}\right): \delta 1.65-1.72(\mathrm{~m}, 6 \mathrm{H}$, $\left.3 \mathrm{xCH}_{2}\right), 2.64\left(\mathrm{~s}, 3 \mathrm{H}, \mathrm{CH}_{3}\right), 3.68-3.72\left(\mathrm{~m}, 4 \mathrm{H}, 2 \mathrm{xCH}_{2}\right)$, 7.68-7.70 (m, 2H, Ar-H), 7.88-7.91 (m, 2H, Ar-H), 8.07$8.10(\mathrm{~m}, 2 \mathrm{H}, \mathrm{Ar}-\mathrm{H}), 8.38$ (s, 1H, Ar-H); ESI-MS m/z 336.13, 254.21, 225.97. Anal. Calcd for $\mathrm{C}_{20} \mathrm{H}_{20} \mathrm{~N}_{2} \mathrm{OS}$ : C, 71.40; H, 5.99; N, 8.33. Found: C, 71.52; H, 5.95; N, 8.37.

\section{[4-Methyl-2-(Naphthalen-2-yl) \\ Thiazol-5- yl](Morpholin-4-yl) Methanone (8b)}

Yield: $78 \%$; mp: $183^{\circ} \mathrm{C}$, LogP: 2.60 , FT-IR $v_{\max }\left(\mathrm{cm}^{-1}\right.$, $\mathrm{KBr}$ pellets): $1679(\mathrm{C}=\mathrm{O}), 1621(\mathrm{C}=\mathrm{C}), 1592(\mathrm{C}=\mathrm{N})$. ${ }^{1} \mathrm{H}-\mathrm{NMR}\left(300 \mathrm{MHz}, \mathrm{DMSO}-\mathrm{d}_{6}\right): \delta 2.64\left(\mathrm{~s}, 3 \mathrm{H}, \mathrm{CH}_{3}\right)$, 3.62-3.65 (m, 4H, 2xCH 2$), 3.70-3.76\left(\mathrm{~m}, 4 \mathrm{H}, 2 \mathrm{xCH}_{2}\right)$, 7.65-7.68 (m, 2H, Ar-H), 7.86-7.90 (m, 2H, Ar-H), 8.10$8.13(\mathrm{~m}, 2 \mathrm{H}, \mathrm{Ar}-\mathrm{H}), 8.35$ (s, 1H, Ar-H); ESI-MS m/z 338.11, 253.91, 226.09. Anal. Calcd for $\mathrm{C}_{19} \mathrm{H}_{18} \mathrm{~N}_{2} \mathrm{O}_{2} \mathrm{~S}$ : C, 67.43; H, 5.36; N, 8.28. Found: C, 67.48; H, 5.39; N, 8.32.

\section{[4-Methyl-2-(Naphthalen-2-yl) \\ Thiazol-5- yl](Thiomorpholin-4-yl)Methanone (8c)}

Yield: $83 \%$; mp: $191^{\circ} \mathrm{C}, \log \mathrm{P}: 3.48$, FT-IR $v_{\max }\left(\mathrm{cm}^{-1}\right.$, $\mathrm{KBr}$ pellets): $1685(\mathrm{C}=\mathrm{O}), 1626(\mathrm{C}=\mathrm{C}), 1600(\mathrm{C}=\mathrm{N})$. ${ }^{1} \mathrm{H}-\mathrm{NMR}\left(300 \mathrm{MHz}, \mathrm{DMSO}-\mathrm{d}_{6}\right): \delta 2.64\left(\mathrm{~s}, 3 \mathrm{H}, \mathrm{CH}_{3}\right)$, 3.62-3.65 (m, 4H, 2xCH 2$), 3.70-3.76\left(\mathrm{~m}, 4 \mathrm{H}, 2 \mathrm{xCH}_{2}\right)$, 7.65-7.68 (m, 2H, Ar-H), 7.86-7.90 (m, 2H, Ar-H), 8.108.13 (m, 2H, Ar-H), 8.35 (s, 1H, Ar-H); ESI-MS m/z 354.12, 254.21, 226.09. Anal. Calcd for $\mathrm{C}_{19} \mathrm{H}_{18} \mathrm{~N}_{2} \mathrm{OS}_{2}$ : C, 64.38; H, 5.12; N, 7.90. Found: C, 64.45; H, 5.18; N, 7.95.

\section{[4-Methyl-2-(Naphthalen-2-yl) Thiazol-5-yl)](4- Methylpiperazin-1-yl) Methanone (8d)}

Yield: $76 \%$; mp: $136^{\circ} \mathrm{C}, \operatorname{LogP}: 3.06$, FT-IR $v_{\max }$ ( $\mathrm{cm}^{-1}, \mathrm{KBr}$ pellets): $1684(\mathrm{C}=\mathrm{O}), 1624(\mathrm{C}=\mathrm{C}), 1597$ $(\mathrm{C}=\mathrm{N}) .{ }^{1} \mathrm{H}-\mathrm{NMR}\left(300 \mathrm{MHz}, \mathrm{DMSO}-\mathrm{d}_{6}\right): \delta 2.28(\mathrm{~s}, 3 \mathrm{H}$, $\left.\mathrm{NCH}_{3}\right), 2.35-3.38\left(\mathrm{~m}, 4 \mathrm{H}, 2 \mathrm{xCH}_{2}\right), 2.64\left(\mathrm{~s}, 3 \mathrm{H}, \mathrm{CH}_{3}\right)$, 3.36-3.39 (m, 4H, 2xCH$)$,7.66-7.69 (m, 2H, Ar-H), 7.84-7.87 (m, 2H, Ar-H), 8.06-8.09 (m, 2H, Ar-H), 8.33 (s, 1H, Ar-H); ESI-MS m/z 351.14, 254.16, 225.90.
Anal. Calcd for $\mathrm{C}_{20} \mathrm{H}_{21} \mathrm{~N}_{3} \mathrm{OS}$ : C, 68.35; H, 6.02; N, 11.96. Found: C, 68.41; H, 6.08; N, 11.91.

\section{[4-Methyl-2-(Naphthalen-2-yl) Thiazol-5-yl)](4- Chloromethylpiperazin-1-yl) Methanone (8e)}

Yield: $85 \%$; mp: $148^{\circ} \mathrm{C}, \operatorname{LogP}: 3.45$, FT-IR $v_{\max }$ ( $\mathrm{cm}^{-1}, \mathrm{KBr}$ pellets): $1680(\mathrm{C}=\mathrm{O}), 1621(\mathrm{C}=\mathrm{C}), 1591$ $(\mathrm{C}=\mathrm{N}) .{ }^{1} \mathrm{H}-\mathrm{NMR}\left(300 \mathrm{MHz}, \mathrm{DMSO}-\mathrm{d}_{6}\right): \delta 2.45-2.53$ $\left(\mathrm{m}, 7 \mathrm{H}, \mathrm{CH} 3\right.$ and $\left.2 \mathrm{xCH}_{2}\right), 3.22-3.29\left(\mathrm{~m}, 4 \mathrm{H}, 2 \mathrm{XCH}_{2}\right)$, 7.56-7.71 (m, 2H, Ar-H), 7.79-7.96 (m, 2H, Ar-H), 8.03$8.10(\mathrm{~m}, 2 \mathrm{H}, \mathrm{Ar}-\mathrm{H}), 8.33$ (s, 1H, Ar-H); ESI-MS m/z 324.14 (M+2), 322.11 ( $\left.\mathrm{M}^{+}\right), 253.91,226.13$. Anal. Calcd for $\mathrm{C}_{20} \mathrm{H}_{20} \mathrm{ClN}_{3} \mathrm{OS}$ : C, 62.25; H, 5.22; N, 10.89. Found: C, 62.19; H, 5.29; N, 10.94 .

\section{Anticonvulsant Screening}

The pharmacological screening of all the title compounds was performed according to the standard procedure specified by the epilepsy branch of the National Institute of Neurological Disorders and Stroke (Kupferberg, 2001).

Male albino mice (Swiss) of 25-30 g were used as investigational animal. Title compounds were suspended in PEG 200 for MES and scPTZ evaluation. The animals were kept at an ambient temperature $22 \pm 1^{\circ} \mathrm{C}$, in groups of six per cage under standard laboratory condition and permitted to free access to food and water (Krall et al., 1978; Clark et al., 1984).

\section{Maximal Electroshock Seizure Test (MES Test)}

Test compounds were delivered as an intraperitoneal (i.p.) injection at dose of 30,100 and $300 \mathrm{mg} / \mathrm{kg}$ body weight and the anticonvulsant potential was measured after $0.5 \mathrm{~h}$ and $4 \mathrm{~h}$ intervals of administration. Maximal electroshock seizures were caused in mice by delivering $60 \mathrm{~Hz}, 50 \mathrm{~mA}$ electrical stimuli for $0.2 \mathrm{~s}$ via ear clip electrodes. Abolition of hind limb tonic extensor component of the seizure in half or more of the animals is termed as protection.

\section{Subcutaneous Pentylenetetrazole Seizure Test (scPTZ)}

The scPTZ primarily pinpoints compounds that elevate seizure threshold. The sc PTZ test employs a dose of pentylenetetrazol $(85 \mathrm{mg} / \mathrm{kg})$. This yields clonic seizures lasting for a period of at least five seconds in 97 percent $\left(\mathrm{CD}_{97}\right)$ of animals tested. Solutions of test compounds were administered intraperitoneally at dose level of 30,100 and $300 \mathrm{mg} / \mathrm{kg}$. At the estimated time of testing $(0.5 \mathrm{~h}$ and $4.0 \mathrm{~h})$, the convulsant (PTZ) was administered subcutaneously and animals were observed over a $30 \mathrm{~min}$ period. Abolition of clonic seizure in half or more of the animals in the observed time period designated a compound's ability to eliminate the effect of pentylenetetrazol on seizure threshold. 


\section{In vitro GABA-Transaminase Inhibition Assay}

As docking study demonstrated that these compounds are binding with gamma aminotransferase enzyme, the most active compounds were screened in vitro against the $\gamma$-amino Butyric Acid-Transaminase (GABA-T) enzyme and the inhibitory activity was evaluated. The GABA-T enzyme was isolated from Pseudomonas fluorescens using a method described previously (Scott and Jakoby, 1958). The assay was performed for a $4 \mathrm{~h}$ time period according to the standard procedure (Lippert et al., 1977).

\section{Neurotoxicity Screening}

The minimal motor damage was measured in mice by the rotarod test. The mice were skilled to hold on speeding up rotarod of diameter $3.2 \mathrm{~cm}$ that rotates at 10 Revolutions Per Minute (RPM). Neurotoxicity was designated by the inability of the animal to withstand equilibration on the rod for at least one minute in each of the three experiments. The dose at which $50 \%$ of the animals qualified to balance themselves and fell off the rotating rod was determined (Dunham and Miya, 1957).

\section{Ethanol Potentiation Test}

Mice were subjected with the minimum test compound (30 mg/kg body weight) and $1 \mathrm{~h}$ later with ethanol $2.5 \mathrm{~g}$ $\mathrm{kg}^{-1} i p$. This dose of ethanol did not bring lateral position in the control animals. The number of animals that were in the lateral position after getting ethanol in each group was determined (Clerici and Pocar, 2001).

\section{Results and Discussion}

\section{Chemistry}

The structures of synthesized analogues were identified by elemental analysis, FT-IR, ${ }^{1} \mathrm{H}$ NMR and mass spectral data. FT-IR spectrum revealed four bands for $\mathrm{NH}, \mathrm{C}=\mathrm{O}$ and $\mathrm{C}=\mathrm{C}$ and $\mathrm{C}=\mathrm{N}$ at $3378-3348 \mathrm{~cm}^{-1}$, $1692-1677 \mathrm{~cm}^{-1}, 1629-1618 \mathrm{~cm}^{-1}$ and $1607-1570 \mathrm{~cm}^{-1}$ respectively. The ${ }^{1} \mathrm{H}$ NMR of 7a-7o confirmed presence of $\mathrm{NHC}=\mathrm{O}$ group exhibiting chemical shift $(\delta)$ in the range of 12.69-9.30 with broad singlet shape and splitting, exchangeable with $\mathrm{D}_{2} \mathrm{O}$ while the same peak was found absent in the compounds 8a-8e. The physical and chemical data for newly synthesized analogues are presented supplementary material.

\section{Anticonvulsant Activity}

The preliminary evaluation of the titled compounds 7a-7o and 8a-8e were evaluated for anticonvulsant activity utilizing the predictable animal models and the neurotoxicity was assessed by rotorod test method. Of these, the MES and $s c$ PTZ seizure models exemplify the most widely used screening models in the search for new anticonvulsant agents. Data are presented "Table 1" after the 0.5 and $4 \mathrm{~h}$ time intervals at the dose level of 30,100 and $300 \mathrm{mg} / \mathrm{kg}$ body weight of the animals. Phenytoin and carbamazepine were used as the standard drugs for the comparison.

The synthesized compounds $\mathbf{7 e}, \mathbf{7 j}, \mathbf{7 n}$ and $\mathbf{8 c}$ showed anticonvulsant potential at the dose level of 30 $\mathrm{mg} / \mathrm{kg}$ after $0.5 \mathrm{~h}$ against the seizure spread indicating rapid onset but shorter duration of action except 8c. Compound 8c displayed protection after $0.5 \mathrm{~h}$ and $4 \mathrm{~h}$ signifying quick onset and long duration of action.

Moreover, compounds $\mathbf{7 b}, \mathbf{7 d}, \mathbf{7 g}, \mathbf{7 h}, \mathbf{7 k}$ and $\mathbf{8 d}$ exhibited MES protection at the dose level $100 \mathrm{mg} / \mathrm{kg}$ at $0.5 \mathrm{~h}$, but after $4 \mathrm{~h}$ these analogues had displayed protection at dose level $300 \mathrm{mg} / \mathrm{kg}$ indicating rapid onset and short duration of action. The other compounds either did not exhibit any protection or showed activity at a dose of $300 \mathrm{mg} / \mathrm{kg}$ which is not significant enough to consider them for other future investigations. As previously discussed only those analogues were selected for anti PTZ screening which had displayed a significant anti MES activity. Therefore, compounds $\mathbf{7 b}, \mathbf{7 d}, \mathbf{7 e}, \mathbf{7 g}$, $\mathbf{7 h}, \mathbf{7 i}, \mathbf{7 j}, \mathbf{7 k}, \mathbf{7 n}$ and $\mathbf{8 d}$ were screened for anti PTZ activity. Analogues $7 \mathbf{h}, \mathbf{7 i}, \mathbf{7 j}$ and $8 \mathbf{c}$ showed potential at $100 \mathrm{mg} / \mathrm{kg}$ dose after $0.5 \mathrm{~h}$. Out of these, two analogues notably $\mathbf{7 h}$ and $\mathbf{7 i}$ showed potential even after $4 \mathrm{~h}$ at an increased dose of $300 \mathrm{mg} / \mathrm{kg}$. The overall outcomes suggested the quick onset of these analogues and short duration of action in anti PTZ potential. A few compounds for example $\mathbf{7 b}, \mathbf{7 d}$ and $\mathbf{7 g}$ showed very less anti PTZ activity and therefore, insignificant to mention.

When we correlate anticonvulsant data with lipophilicity $(\log \mathrm{P})$ data, it is quite obvious that the lipophilicity is not the only factor which diktats the anticonvulsant activity. Therefore, compound $7 \mathbf{e}(\log \mathrm{P}=$ $6.50)$ and $7 \mathbf{j}(\log \mathrm{P}=7.13)$ showed high activity against MES. But the other two highly active compounds $\mathbf{7 n}$ and 8c showed low lipophilicity (log $\mathrm{P}$ values are 4.14 and 3.4 respectively). $\log \mathrm{P}$ values of the titled analogues are shown in supplementary material.

The four most active compounds $(\mathbf{7 e}, \mathbf{7 j}, \mathbf{7 n}$ and $\mathbf{8 c})$ were subjected to in vitro GABA-T inhibition assay to establish the mechanism involved in the anticonvulsant potential of the title analogues. The GABA-transaminase enzyme has been found to be accountable for the metabolism of GABA and therefore, inhibition of the enzyme will cause in an elevated amount of GABA in various brain parts. The results of the assay are offered in "Table 2". All four analogues were observed to inhibit the GABA-T enzyme at the $4 \mathrm{~h}$ time period. Compound 7d was found to inhibit GABA-T almost throughout the time periods, but the full inhibition shown by $\mathbf{7 d}$ was $20 \%$ at $4 \mathrm{~h}$. Compound $7 \mathbf{n}$ inhibited the enzyme at $1 \mathrm{~h}$ and maximum inhibition (12\%) was detected at $4 \mathrm{~h}$. Compound $7 \mathbf{j}$ demonstrated second maximum inhibition amongst these compounds. It displayed inhibition at $2 \mathrm{~h}$ and continued to inhibit the enzyme considerably throughout the time periods. Compound 8cexhibited less enzyme inhibition and maximum inhibition was witnessed at $4 \mathrm{~h}(11 \%)$. 
Table 1: Anticonvulsant and neurotoxicity screen data of compounds (7a-o; 8a-e)

\begin{tabular}{|c|c|c|c|c|c|c|c|}
\hline & \multicolumn{2}{|c|}{ MES screening } & \multicolumn{2}{|c|}{ scPTZ screening } & \multicolumn{2}{|c|}{ Neurotoxicity screen } & \multirow{2}{*}{$\begin{array}{l}{ }^{\mathrm{a}} \text { Ethanol } \\
\text { Potentiation }\end{array}$} \\
\hline & $0.5 \mathrm{~h}$ & $4.0 \mathrm{~h}$ & $0.5 \mathrm{~h}$ & $4.0 \mathrm{~h}$ & $0.5 \mathrm{~h}$ & $4.0 \mathrm{~h}$ & \\
\hline $7 \mathbf{a}$ & 300 & $(-)$ & $\mathrm{X}$ & $\mathrm{X}$ & $\mathrm{X}$ & $\mathrm{X}$ & $\mathrm{X}$ \\
\hline $7 \mathbf{b}$ & 100 & 300 & 300 & $(-)$ & $(-)$ & $(-)$ & $(-)$ \\
\hline $7 c$ & $(-)$ & 300 & $\mathrm{X}$ & $\mathrm{X}$ & $\mathrm{X}$ & $\mathrm{X}$ & $\mathrm{X}$ \\
\hline $7 d$ & 100 & 300 & $(-)$ & 300 & $(-)$ & $(-)$ & $(-)$ \\
\hline $7 e$ & 30 & 100 & 300 & $(-)$ & 100 & 300 & $(+)$ \\
\hline $7 f$ & 300 & $(-)$ & $\mathrm{X}$ & $\mathrm{X}$ & $\mathrm{X}$ & $\mathrm{X}$ & $\mathrm{X}$ \\
\hline $7 \mathrm{~g}$ & 100 & 300 & 300 & $(-)$ & $(-)$ & $(-)$ & $(-)$ \\
\hline $7 \mathrm{~h}$ & 100 & 300 & 100 & 300 & $(-)$ & $(-)$ & $(-)$ \\
\hline $7 \mathbf{i}$ & 100 & $(-)$ & 100 & 300 & 300 & $(-)$ & $(+)$ \\
\hline $7 \mathbf{j}$ & 30 & 300 & 100 & $(-)$ & $(-)$ & $(-)$ & $(-)$ \\
\hline $7 \mathbf{k}$ & 100 & 300 & $(-)$ & $(-)$ & $(-)$ & $(-)$ & $(-)$ \\
\hline 71 & $(-)$ & 300 & $(-)$ & $(-)$ & $\mathrm{X}$ & $\mathrm{X}$ & $\mathrm{X}$ \\
\hline $7 m$ & $(-)$ & $(-)$ & $(-)$ & 300 & $\mathrm{X}$ & $\mathrm{X}$ & $\mathrm{X}$ \\
\hline $7 n$ & 30 & 300 & $(-)$ & $(-)$ & $(-)$ & $(-)$ & $(-)$ \\
\hline 70 & $(-)$ & 300 & $(-)$ & $(-)$ & $\mathrm{X}$ & $\mathrm{X}$ & $\mathrm{X}$ \\
\hline $8 \mathbf{a}$ & $(-)$ & $(-)$ & $\mathrm{X}$ & $\mathrm{X}$ & $X$ & $X$ & $X$ \\
\hline $8 b$ & 300 & $(-)$ & $\mathrm{X}$ & $\mathrm{X}$ & $\mathrm{X}$ & $\mathrm{X}$ & $\mathrm{X}$ \\
\hline $8 c$ & 30 & 30 & 100 & $(-)$ & $(-)$ & $(-)$ & $(-)$ \\
\hline $8 d$ & 100 & 300 & $(-)$ & 300 & $(-)$ & $(-)$ & $(+)$ \\
\hline $8 \mathbf{e}$ & 300 & 300 & $\mathrm{X}$ & $\mathrm{X}$ & $\mathrm{X}$ & $\mathrm{X}$ & $\mathrm{X}$ \\
\hline Phenytoin & 30 & 30 & $(-)$ & $(-)$ & 100 & 100 & $\mathrm{X}$ \\
\hline Carbamazepine & 30 & 100 & 100 & 300 & 100 & 300 & $\mathrm{X}$ \\
\hline
\end{tabular}

30,100 and $300 \mathrm{mg} / \mathrm{kg}$ body weight doses of the title analogues were delivered and the protection and neurotoxicity were estimated after 0.5 and $4 \mathrm{~h}$. The figures pointed out the lowest dose required to show protection or neurotoxicity in $50 \%$ or more of the animals. The dash (-) represents the absence of anticonvulsant potential or neuro-motor impairment. X represents not tested. ${ }^{a}$ Ethanol potentiation test: $(+)$, half or more animals passed the test; $(-)$, half or more animals failed the test. X represents not tested.

Table 2: In vitro GABA-transaminase inhibition evaluation of selected compounds

\begin{tabular}{|c|c|c|c|c|c|}
\hline \multirow[b]{2}{*}{ Compd. No. } & \multicolumn{5}{|c|}{ Percentage inhibition of GABA-T } \\
\hline & $0.5 \mathrm{~h}$ & $1.0 \mathrm{~h}$ & $2.0 \mathrm{~h}$ & $3.0 \mathrm{~h}$ & $4.0 \mathrm{~h}$ \\
\hline Control & - & - & - & - & - \\
\hline $7 e$ & - & 08 & 12 & 15 & 20 \\
\hline $7 \mathbf{j}$ & - & - & 9 & 13 & 18 \\
\hline $7 n$ & - & 5 & 8 & 10 & 12 \\
\hline $8 c$ & - & $\longrightarrow$ & - & 7 & 11 \\
\hline
\end{tabular}

${ }^{a}$ In vitro enzyme inhibition was performed at a dose of $500 \mu \mathrm{M}$ for each compounds

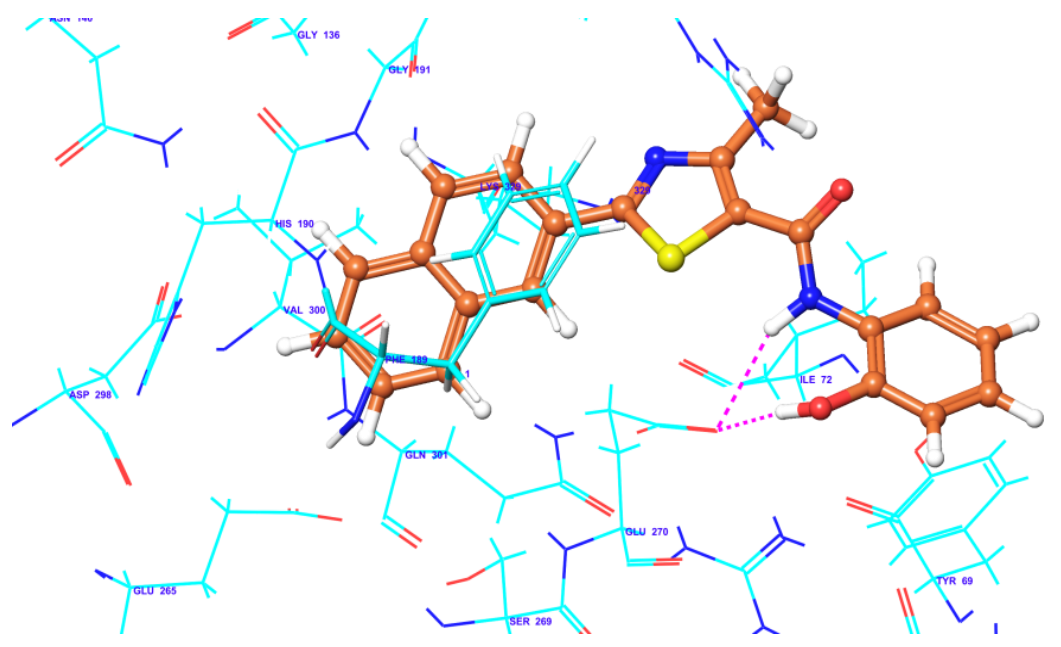

Fig. 3: Highest ligand scoring compound with catalytic domain of GABA aminotransferase protein 


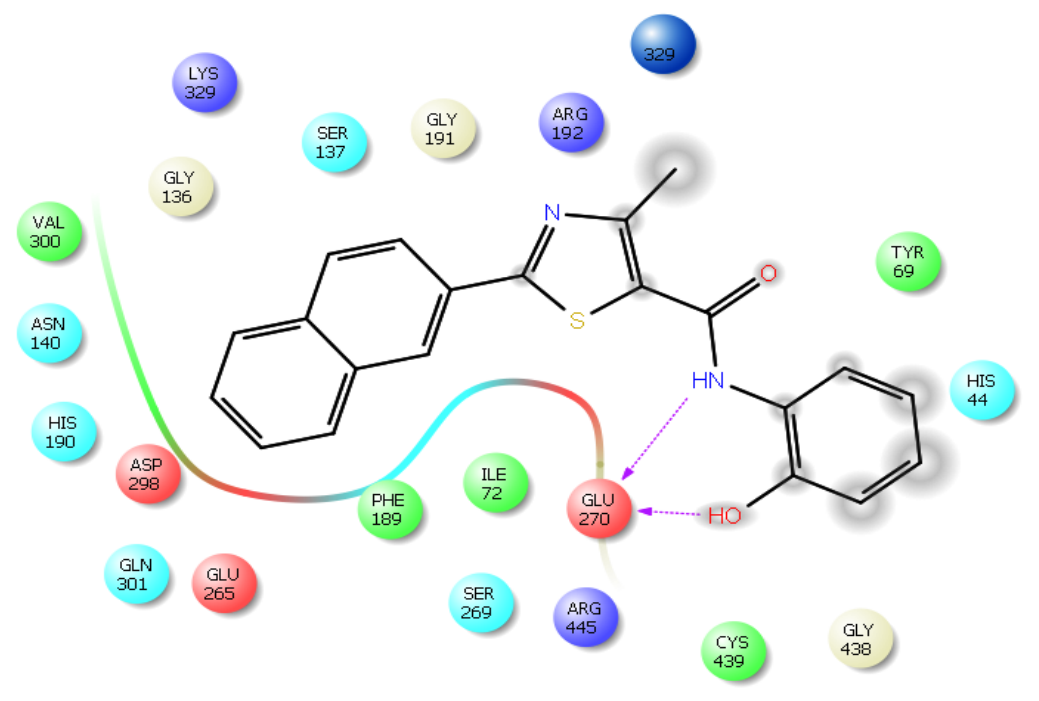

Fig. 4: Lig-plot: Highest ligand scoring compound 7k with catalytic domain of GABA aminotransferase protein

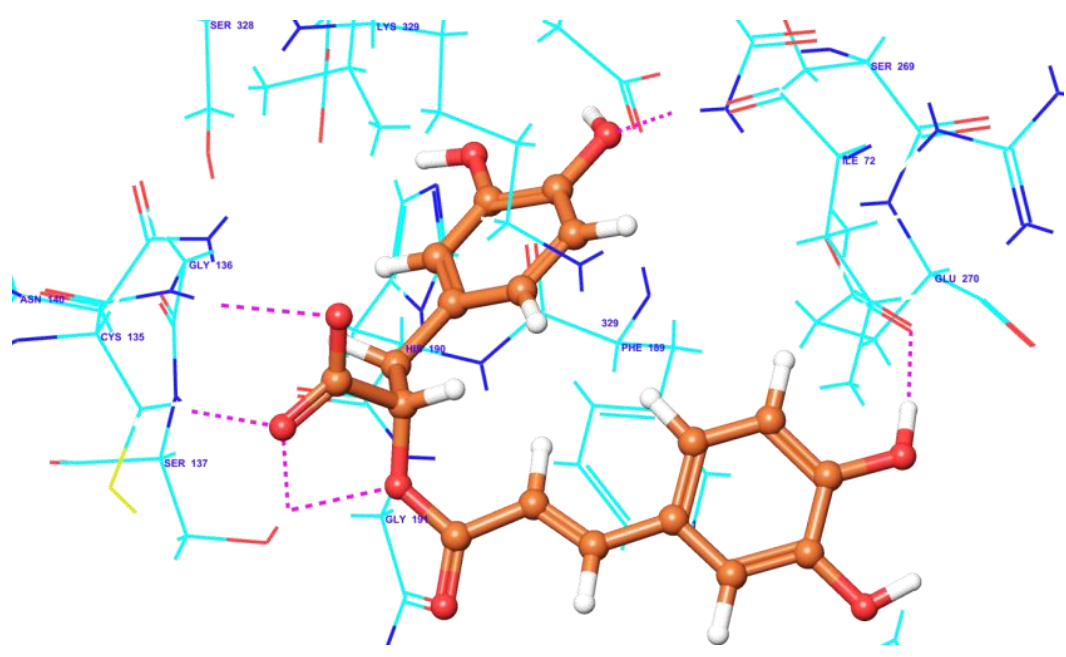

Fig. 5: Binding pose of rosmarinic acid (standard) with GABA aminotransferase protein

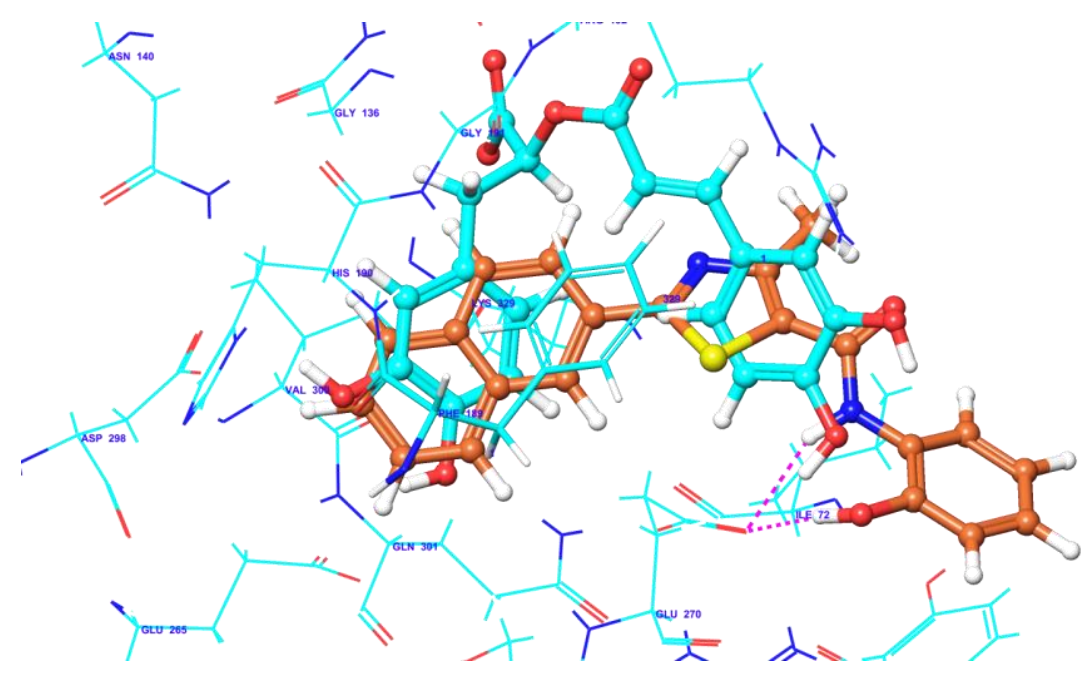

Fig. 6: Superimposition of rosmarinic acid (cyan) with highest ligand scoring compound (grey). 
Only those compounds were selected for neurotoxicity screening, which had shown good to moderate anticonvulsant activity.

Compound 7e showed considerable neuro-motor impairment at a dose of $100 \mathrm{mg} / \mathrm{kg}$ in the rotorod test, whereas compound $\mathbf{7 i}$ showed neurotoxicity at an increased dose of $300 \mathrm{mg} / \mathrm{kg}$. The rest of the compounds did not show any neuro-motor impairment in rotorod test. Compounds 7e, 7i and 8d showed an interaction with motor system, due to which they potentiated the effect of ethanol inducing the lateral position to the animals. The rest of the analogues did not display any interaction with ethanol at minimum dose of $30 \mathrm{mg} / \mathrm{kg}$ (Table 1).

We performed molecular docking on synthesized compounds 7a-7o \& $\mathbf{8 a - 8 e}$ against GABA aminotransferase and the docking studies revealed a common binding orientation of all the synthesized compounds in the catalytic binding pocket of GABA aminotransferase. Figure 3 shows highest ligand scoring compound with catalytic domain of GABA aminotransferase protein.

Log plot of highest ligand scoring analogue $7 \mathbf{k}$ with catalytic domain of GABA aminotransferase protein is offered in Fig. 4.

Binding pose of rosmarinic acid (standard) with GABA aminotranseferase protein has been presented in Fig. 5. Figure 6 shows superimposition of rosmarinic acid (cyan) with highest ligand scoring compound (grey).

The binding pose of compound (7k) has been compared with the standard co-crystal ligand which is bonded with GABA aminotransferase protein. The thiazole moiety of the compound indirectly plays a significant role in binding with the amino acid. The nitrogen atom of amino group is involved in hydrogen bonding interactions with amino acid residue Glu270 and 2hydroxy substitution on phenyl ring forms hydrogen bonding with Glu270 at the catalytic site (Fig. 3-6). Hydrophobic amino acids Gly438, Cys439, Arg445, Ile72, Phe189, Glu265, Gln301, Asp298, His190, Asn140 and Val300 appeared as a cup like structure (Fig. 3-6). In addition, the naphthalene moiety shows hydrophobic interaction with GABA amino transferase protein PHE189, VAL300, HIS190 and GLN301 amino acid residues. It was also observed that ortho substitution in phenyl moiety of $\mathbf{7 k}$ gives better interaction with backbone of GABA aminotransferase protein. The hydrogen bonding interaction may probably cause the inhibition of GABA aminotransferase enzyme.

\section{Conclusion}

$\beta$-Naphthalene incorporated thiazole-5carboxamides/thiazole -5- ketones were synthesized and evaluated for their anticonvulsant activity utilizing MES and $s c$ PTZ animal models. Neuro-motor impairment was assessed by rotorod and ethanol potentiation methods.
Majority of these compounds exhibited significant activity against both animal models; however, compounds $\mathbf{7 e}, \mathbf{7 j}, \mathbf{7 n}$ and $\mathbf{8 c}$ emerged as highly active. These highly potent analogues did not show any sign of neuromotor impairment when they were subjected to rotorod and ethanol potentiation tests. Docking analysis and GABA-transaminase inhibitory assay suggested the mechanism of action of these analogues. All these experimental data revealed that these compounds might serve as lead candidates for further design and development of anticonvulsant agents with low toxicity and high efficacy.

\section{Acknowledgement}

The authors appreciate Shaqra University (KSA) for providing various facilities to conduct this research work.

\section{Author's Contributions}

Mohammed Faiz Arshad: Designed the concept of this work and contributed in all sections.

Faisal Al-Otaibi: Performed antiepileptic activity of the title compounds.

Gulam Mustafa: Performed docking studies and partly contributed in synthesis of the title compounds.

Saad Shousha: Contributed in toxicity evaluation.

Abdulrahman Alshahrani: Contributed in characterization of the title compounds and also contributed in synthetic work.

\section{Conflict of Interest}

The authors affirm that there is no conflict of interest concerning the publication of this work.

\section{References}

Al-Otaibi, F., 2019. An overview of structurally diversified anticonvulsant agents. Acta Pharm., 69: 1-24. DOI: 10.2478/acph-2019-0023

Al-Rajeh, S., A. Awada, O. Bademosi and A. Ogunniyi, 2001. The prevalence of epilepsy and other seizure disorders in an Arab population: A communitybased study. Seizure, 10: 410-414.

DOI: 10.1053/seiz.2001.0602

Amin, K.M., A.D.E. Rahman and Y.A. Al-Eryani, 2008. Synthesis and preliminary evaluation of some substituted coumarins as anticonvulsant agents. Bioorg. Med. Chem., 16: 5377-5388.

DOI: 10.1016/j.bmc.2008.04.021

Brodie, M.J., 1990. Established anticonvulsants and treatment of refractory epilepsy. Lancet, 336: 350-354. DOI: 10.1016/0140-6736(90)91886-F 
Chang, B.S. and D.H. Lowenstein, 2003. Epilepsy. N. Engl. J. Med., 349: 1257-1266.

DOI: $10.1056 /$ NEJMra022308

Clark, C.R., M.J.M. Wells, R.T. Sansom, G.N. Norris and R.C. Dockens et al., 1984. Anticonvulsant activity of some 4-aminobenzamides. J. Med. Chem., 27: 779-782. DOI: 10.1021/jm00372a013

Clerici, F. and D. Pocar, 2001. Synthesis of 2-amino-5sulfanyl-1,3,4-thiadiazole derivatives and evaluation of their antidepressant and anxiolytic activity. J. Med. Chem. 44: 931-936. DOI: $10.1021 / \mathrm{jm} 001027 \mathrm{w}$

Dunham, N.W. and T.A. Miya, 1957. A note on a simple apparatus for detecting neurological deficit in rats and mice. J. Am. Pharm. Assoc. Sci., 46: 208-209. DOI: $10.1002 /$ jps.3030460322

Hess, R., 1985. Handbook of Experimental Pharmacology. In: Antiepileptic Drugs, Frey, H.H. and D. Janz (Eds.), Springer Verlag, Berlin, pp: 35-36.

Karakurt, A., M. Ozalp, S. Işik, J.P. Stables and S. Dalkara, 2010. Synthesis, anticonvulsant and antimicrobial activities of some new 2acetylnaphthalene derivatives. Bioorg. Med. Chem., 18: 2902-2911. DOI: 10.1016/j.bmc.2010.03.010

Karakurt, A., M.A. Alagöz, B. Sayoğlu, U. Calış and S. Dalkara, 2012. Synthesis of some novel 1-(2naphthyl)-2-(imidazol-1-yl)ethanone oxime ester derivatives and evaluation of their anticonvulsant activity. Eur. J. Med. Chem., 57: 275-282.

DOI: 10.1016/j.ejmech.2012.08.037

Karakurt, A., M.D. Aytemir, J.P. Stables, M. Ozalp and F.B. Kaynak et al., 2006. Synthesis of some oxime ether derivatives of 1-(2-naphthyl)-2-(1, 2, 4-triazol1-yl) ethanone and their anticonvulsant and antimicrobial activities Arch. Pharm., 339: 513-520. DOI: 10.1002/ardp.200500248

Karakurt, A., S. Dalkara, M. Ozalp, S. Ozbey and E. Kendi et al., 2001. Synthesis of some 1-(2naphthyl)-2-(imidazole-1-yl)ethanone oxime and oxime ether derivatives and their anticonvulsant and antimicrobial activities. Eur. J. Med. Chem., 36: 421-433. DOI: 10.1016/S0223-5234(01)01223-5
Koufaki, M., C. Kiziridi, F. Nikoludaki and M.N. Alexis, 2007. Design and synthesis of 1,2-dithiolane derivatives and evaluation of their neuroprotective activity, Bioorg. Med. Chem. Lett., 17: 4223-4227. DOI: 10.1016/j.bmcl.2007.05.036

Krall, R.L., J.K. Penry, B.G. White, H.J. Kupferberg and E.A. Swinyard, 1978. Antiepileptic drug development: II. Anticonvulsant drug screening. Epilepsia, 19: 409-428. DOI: $10.1111 / \mathrm{j} .1528-1157.1978 . t b 04507 . \mathrm{x}$

Kupferberg, H., 2001. Animal models used in the screening of antiepileptic drugs. Epilepsia, 42: 7-12. DOI: 10.1046/j.1528-1157.2001.00002.x

Lippert, B., B.W. Metcalf, M.J. Jung and P. Casara, 1977. 4-Amino-hex-5-enoic acid, a selective catalytic inhibitor of 4-aminobutyyric aminotransferase in mammalian brain. Eur. J. Biochem., 74: 441-445.

DOI: 10.1111/j.1432-1033.1977.tb11410.x

Ozdemir, Z., A. Karakurt, U. Caliş, S. Günal and S. Işik et al., 2014. Synthesis, anticonvulsant and antimicrobial activities of some new [1-(2naphthyl)-2-(pyrazol-1-yl)ethanone]oxime ethers. Med. Chem., 11: 41-49. DOI: $10.2174 / 1573406410666140428150358$

Robert, F.S., C. Acevedo, A. Arzimanoglou, A. Bogacz and J.H. Cross et al., 2014. ILAE official report: A practical clinical definition of epilepsy. Epilepsia, 55: 475-482. DOI: 10.1111/epi.12550

Scott, E.M. and W.B. Jakoby, 1958. Pyrrolidine metabolism: Soluble gamma aminobutyric acid transaminase and semialdehyde dehydrogenase. Science, 128: 361-362.

DOI: $10.1126 /$ science.128.3320.361-a

Thurman, D.J., E. Beghi, C.E. Begley, A.T. Berg and J.R. Buchhalter, 2011. Standards for epidemiologic studies and surveillance of epilepsy. Epilepsia, 52: 2-26. DOI: 10.1111/j.1528-1167.2011.03121.x 